\title{
Stathmin gene silencing suppresses proliferation, migration and invasion of gastric cancer cells via AKT/sCLU and STAT3 signaling
}

\author{
FENG SHU ${ }^{1 *}$, XIAOQIN ZOU ${ }^{1 *}$, HUAN TUO $^{1}$, SHA SHE $^{1}$, JUAN HUANG $^{1}$, HONG REN $^{1-3}$, \\ HUAIDONG HU ${ }^{1-3}$, SHIFANG PENG ${ }^{1-4}$, JIANDONG WANG ${ }^{1-5}$ and YIXUAN YANG ${ }^{1 *}$
}

\begin{abstract}
${ }^{1}$ Department of Infectious Diseases, The Second Affiliated Hospital of Chongqing Medical University, Chongqing 400010; ${ }^{2}$ Institute for Viral Hepatitis of Chongqing Medical University; ${ }^{3}$ Key Laboratory of Molecular Biology for Infectious Diseases, Ministry of Education, Chongqing Medical University, Chongqing 400016; ${ }^{4}$ Department of Hepatology and Infectious Diseases, Xiangya Hospital, Central South University, Changsha, Hunan 410013; ${ }^{5}$ Department of Gynecological Oncology, Beijing Obstetrics and Gynecology Hospital, Capital Medical University, Beijing 100069, P.R. China
\end{abstract}

Received March 20, 2018; Accepted November 2, 2018

DOI: $10.3892 /$ ijo.2019.4674

\begin{abstract}
Globally, gastric cancer is the fifth most common malignancy, with high rates of incidence and mortality. The high mortality rate and poor prognosis of gastric cancer are closely associated with its profound invasiveness, high incidence of metastasis, rapid proliferation, and high rate of recurrence. Previous studies have confirmed that stathmin (STMN) has an important role in the occurrence, development and prognosis of gastric cancer. However, the detailed mechanisms by which STMN affects these processes remain unclear. The aim of the present study was to determine how STMN promotes invasion, migration and proliferation in gastric cancer tumor cells. The results of immunohistochemistry indicated that STMN is overexpressedinstomachneoplasmtissues, and that it is associated with migration, invasion, proliferation and anti-apoptotic states of gastric cancer cells. The secretory proteins of gastric cancer cells with or without STMN knockdown were further analyzed using the isobaric tags for relative and absolute quantitation
\end{abstract}

Correspondence to: Professor Yixuan Yang, Department of Infectious Diseases, The Second Affiliated Hospital of Chongqing Medical University, 76 Linjiang Road, Yuzhong, Chongqing 400010, P.R. China

E-mail: yxyang15123@sina.com

Professor Jiandong Wang, Department of Gynecological Oncology, Beijing Obstetrics and Gynecology Hospital, Capital Medical University, 10 West Gate, Right Wing Gate, Fengtai, Beijing 100069, P.R. China

E-mail: wangjiandongxy@hotmail.com

${ }^{*}$ Contributed equally

Key words: gastric cancer, stathmin, isobaric tags for relative and absolute quantitation, clusterin, matrix metalloproteinases, protein kinase $\mathrm{B}$, signal transducer and activation of transcription method to identify differentially expressed proteins verified by reverse transcription-quantitative polymerase chain reaction and western blot analysis. Inhibition of STMN decreases the levels of clusterin, cystatin $\mathrm{C}$ and matrix metalloproteinases, followed by inhibiting the protein kinase $\mathrm{B}$ and signal transducer and activation of transcription activation. These findings suggest that STMN could be a promising therapeutic target for gastric cancer.

\section{Introduction}

Globally, gastric cancer (GC) is the fifth most common malignant tumor and the third leading cause of cancer-related mortality (1). The 5-year survival rate of GC remains low (25\%) (2,3). Although great progress has been made in the availability of treatment techniques for $\mathrm{GC}$, the prognosis for GC patients remains poor due to the biological properties of tumor cells, including a high propensity for invasiveness and metastasis, rapid proliferation, and anti-apoptotic behavior (4). Therefore, studying the pathogenesis of GC may improve the diagnosis, treatment and prognosis of GC. Recently, the migration, invasion and other biological functions of $\mathrm{GC}$ have attracted considerable attention, and various proteins and signaling pathways associated with the invasiveness and metastasis of GC in patients have been found (5-7). However, many of the molecular mechanisms of GC metastasis remain unknown.

Stathmin (STMN) is a microtubule-regulating protein that has a critical role in the aggregation and depolymerization of mitotic spindles. In previous studies, STMN overexpression has been demonstrated in a variety of tumors and to contribute to the occurrence and development of gastrointestinal malignancies (8-11). In addition, previous studies have confirmed that STMN is associated with cell differentiation, proliferation and prognosis in tumors, particularly in correlation with migration and invasion of GC cells (12-14). These findings indicate that STMN could be a potential molecular marker and target in GC gene therapy. However, 
few studies have focused on the mechanism by which STMN promotes migration and invasion in stomach neoplasm.

In the present study, the isobaric tags for relative and absolute quantitation (iTRAQ) methodology was used to identify the differentially expressed proteins (DEPs) in GC cells with or without silencing of the STMN gene. Following verification and further analysis by reverse transcription-quantitative polymerase chain reaction (RT-qPCR) and western blotting, the DEPs clusterin, cystatin $\mathrm{C}$, and matrix metalloproteinases (MMPs) were focused on, which have recently been reported to be closely associated with metastasis and invasiveness in malignant tumors. Additionally, the biological processes of STMN-silenced GC cells were studied. Elucidating the underlying molecular mechanisms in STMN-induced GC metastasis may provide a theoretical basis for gene therapy in GC patients, and a novel pathway was identified that may be responsible for the promotional effect of STMN in GC metastases.

\section{Materials and methods}

Reagents. Eight-plex iTRAQ kits were purchased from Applied Biosystems; Thermo Fisher Scientific, Inc. (Waltham, MA, USA). All electrophoresis reagents used in this study were acquired from Bio-Rad Laboratories, Inc. (Hercules, CA, USA). CytoSelect ${ }^{\mathrm{TM}}$ 24-well Cell Migration and Invasion assay kits ( $8 \mu \mathrm{m}$, colorimetric format) were purchased from Cell Biolabs, Inc. (San Diego, CA, USA). Opti-MEM was purchased from Gibco; Thermo Fisher Scientific, Inc. Lipofectamine 2000, STMN-specific small interfering (si) RNA oligonucleotides (HSS180637 and HSS142799) and a negative control (12935-400) were acquired from Invitrogen; Thermo Fisher Scientific, Inc. Monoclonal antibodies against STMN (TA325913S) and apolipoprotein E (APOE; TA805358) were obtained from OriGene Technologies, Inc. (Rockville, MD, USA). Antibodies against LI Cadherin (CDH17; ab109220), clusterin (sCLU; ab92548), cystatin-C (CST3; ab133495), cathepsin D (CTSD; ab134169), fascin (FSCN; ab126772), heat shock protein 90 (HSP90; ab13492), MMP9 (ab38898), MMP1 (ab137332), signal transducer and activation of transcription (STAT3; ab68153), phosphorylated (p)-STAT3 (ab76315), protein kinase B (AKT; ab8805), p-AKT (ab38449), cyclin-dependent kinase 1 (CDK1; ab18) and superoxide dismutase 1 (SOD1; ab13498) were acquired from Abcam (Cambridge, MA, USA).

Patients and cell lines. The tumor specimens used in this study were 40 samples obtained from 40 GC patients (11 female and 29 male patients; mean age, 59 years) who underwent curative resection at Infectious Disease Department of the Second Affiliated Hospital of Chongqing Medical University between September 2015 and October 2016 (Chongqing, China; Table I). All the studied cases met the following conditions: i) Patients with resectable GC; ii) diagnosed via at least two types of examination; iii) clinical staging was made by at least two types of imaging examination; iv) patients without preoperative chemotherapy orradiotherapy; and v) patients without a history of a drug-related allergy. Among the clinical patients, the majority of GC patients had neoplasm of intermediate differentiation (stage III or IV). Non-cancerous tissues were obtained from the distal edge of the resection, $\geq 10 \mathrm{~cm}$ from the GC tissues. All methods used in the present study were approved by the Ethics Committee of Chongqing Medical University (Chongqing, China), and all patients provided written informed consent prior to participation. The human GC cell line (AGS) was purchased from the American Type Culture Collection (Manassas, VA, USA), grown in Dulbecco's modified Eagle's medium (DMEM; GE Healthcare Life Sciences, Logan, UT, USA) medium supplemented with $10 \%$ fetal bovine serum (FBS; Gibco; Thermo Fisher Scientific, Inc.) and penicillin, and incubated in an atmosphere of $5.0 \% \mathrm{CO}_{2}$ at $37^{\circ} \mathrm{C}$.

Immunohistochemistry (IHC) and tissue microarrays. Tissue microarrays, containing $40 \mathrm{GC}$ tissues and 40 adjacent non-cancerous gastric tissues (ST801a; Alenabio, Xian, China) were procured from US Biomax, Inc. (Rockville, MD, USA). The tissue samples were fixed $\left(24 \mathrm{~h}, 4^{\circ} \mathrm{C}\right)$ with $1 \%$ formalin, embedded in paraffin and cut into sections (thickness, $5 \mu \mathrm{m}$ ). Following dewaxing with xylene, the sections were rehydrated using a descending alcohol series (100, 95 and 70\%). The samples were washed thrice with PBS (5 min/wash) and subjected to heat-induced $\left(100^{\circ} \mathrm{C}\right)$ antigen retrieval in a $0.01 \mathrm{M}$ sodium citrate buffer for $5 \mathrm{~min}$. Endogenous peroxidase activity was quenched with $3 \% \mathrm{H}_{2} \mathrm{O}_{2}(10 \mathrm{~min})$. The sections were blocked with $5 \%$ bovine serum albumin (Beijing Solarbio Science \& Technology Co., Ltd., Beijing, China) for $0.5 \mathrm{~h}$ and incubated with primary antibodies against STMN (1:100) overnight at $4^{\circ} \mathrm{C}$. Detection was performed on an Envision/Horseradish Peroxidase system (K4006; DakoCytomation, Glostrup, Denmark), and all slides were counterstained at room temperature with Gill's hematoxylin for $1 \mathrm{~min}$, dehydrated and mounted for light microscope analysis (magnification, x20).

The IHC score was used to evaluate the different expression of stathmin in GC and non-cancerous tissues. The score was calculated as the product of the percentage of positive cells and the intensity of staining. Staining intensity scoring criteria were as follows: No staining scored 0, yellow staining scored 1, yellow-brown staining scored 2, and brown staining scored 3. Scoring for the proportion of positive cells in the scale was performed as follows: The number of positive cells $<10 \%$ scored $0,10-40 \%$ scored $1,40-70 \%$ scored 2 and $>70 \%$ scored 3 .

STMN siRNA transfection. AGS cells were transfected with $50 \mathrm{nM}$ of either STMN-specific siRNA (Invitrogen; Thermo Fisher Scientific, Inc.), a negative control siRNA (12935-400) or blank control using Lipofectamine 2000 (Life Technologies; Thermo Fisher Scientific, Inc.), according to the manufacturer's protocol, and opti-MEM (Gibco). Following transfection, the cells were cultured $\left(37^{\circ} \mathrm{C}\right)$ in high-glucose DMEM supplemented with $10 \%$ FBS. Following $48 \mathrm{~h}$ of incubation, follow-up experiments were performed, siRNA sequences used were as follows: STMN1 siRNA, 5'-AGCCCUCGGUCAAAAGA AU-3'; STMN2 siRNA, 5'-CAACAUCUAUACUUACGAU-3'; STMN3 siRNA, 5'-CUGUCUAGAUGCAACUUUU-3' and negative control siRNA, 5'-UUCUCCGAACGUGUCACGU-3'.

Protein collection and ITRAQ labeling. Secretory proteins of AGS were collected, filtered with a needle filter, and 
Table I. Clinical and pathological data of 40 gastric cancer patients.

\begin{tabular}{|c|c|c|c|c|c|c|c|c|}
\hline Sample no. & Sex & Age (years) & Tumor position & Pathology & Grade & Stage & TNM & Type \\
\hline 1 & $\mathrm{~F}$ & 78 & Stomach & Adenocarcinoma & 1 & II & T3N0M0 & Malignant \\
\hline 2 & M & 67 & Stomach & Adenocarcinoma & 1 & IB & T2N0M1 & Malignant \\
\hline 3 & $\mathrm{~F}$ & 59 & Stomach & Adenocarcinoma & 1 & II & T3N0M0 & Malignant \\
\hline 4 & M & 50 & Stomach & Adenocarcinoma & 1 & II & T3N0M0 & Malignant \\
\hline 5 & $\mathrm{~F}$ & 51 & Stomach & Adenocarcinoma & 1 & II & T3N0M0 & Malignant \\
\hline 6 & $\mathrm{~F}$ & 68 & Stomach & Adenocarcinoma & 2 & $\mathrm{Ib}$ & T2N0M0 & Malignant \\
\hline 7 & M & 48 & Stomach & Adenocarcinoma & 1 & $\mathrm{Ib}$ & T2N0M0 & Malignant \\
\hline 8 & M & 56 & Stomach & Adenocarcinoma & 2 & IB & T2bN0M0 & Malignant \\
\hline 9 & M & 57 & Stomach & Adenocarcinoma & 2 & IB & T2bNOM0 & Malignant \\
\hline 10 & M & 74 & Stomach & Adenocarcinoma & 2 & II & T3N0M0 & Malignant \\
\hline 11 & M & 52 & Stomach & Adenocarcinoma & 2 & II & T3N0M0 & Malignant \\
\hline 12 & M & 68 & Stomach & Adenocarcinoma & 2 & II & T3N0M0 & Malignant \\
\hline 13 & M & 51 & Stomach & Adenocarcinoma & 2 & II & T3N0M0 & Malignant \\
\hline 14 & $\mathrm{~F}$ & 55 & Stomach & Adenocarcinoma & 2 & II & T3N0M0 & Malignant \\
\hline 15 & M & 53 & Stomach & Adenocarcinoma & 2 & II & T3N0M0 & Malignant \\
\hline 16 & M & 54 & Stomach & Adenocarcinoma & 2 & $\mathrm{Ib}$ & T2N0M0 & Malignant \\
\hline 17 & M & 69 & Stomach & Adenocarcinoma & 2 & II & T3N0M0 & Malignant \\
\hline 18 & M & 72 & Stomach & Adenocarcinoma & 3 & II & T3N0M0 & Malignant \\
\hline 19 & M & 56 & Stomach & Adenocarcinoma & 3 & II & T3N0M0 & Malignant \\
\hline 20 & $\mathrm{~F}$ & 53 & Stomach & Adenocarcinoma & 3 & II & T3N0M0 & Malignant \\
\hline 21 & M & 61 & Stomach & Adenocarcinoma & 2 & IIIA & T3N1M0 & Malignant \\
\hline 22 & M & 49 & Stomach & Adenocarcinoma & 2 & II & T3N0M0 & Malignant \\
\hline 23 & M & 53 & Stomach & Adenocarcinoma & 3 & II & T3N0M0 & Malignant \\
\hline 24 & M & 54 & Stomach & Adenocarcinoma & 3 & II & T3N0M0 & Malignant \\
\hline 25 & M & 50 & Stomach & Adenocarcinoma & 3 & II & T3N0M0 & Malignant \\
\hline 26 & $\mathrm{~F}$ & 63 & Stomach & Adenocarcinoma & 3 & II & T3N0M0 & Malignant \\
\hline 27 & $\mathrm{~F}$ & 68 & Stomach & Adenocarcinoma & 3 & $\mathrm{I}$ & T2N0M0 & Malignant \\
\hline 28 & M & 71 & Stomach & Adenocarcinoma & 3 & IIIA & T3N1M0 & Malignant \\
\hline 29 & M & 61 & Stomach & Adenocarcinoma & 3 & $\mathrm{Ib}$ & T2N0M0 & Malignant \\
\hline 30 & M & 47 & Stomach & Adenocarcinoma & 3 & II & T2N1M0 & Malignant \\
\hline 31 & M & 58 & Stomach & Adenocarcinoma & 3 & II & T3N0M1 & Malignant \\
\hline 32 & $\mathrm{~F}$ & 63 & Stomach & Adenocarcinoma & 3 & $\mathrm{Ib}$ & T2N0M0 & Malignant \\
\hline 33 & M & 66 & Stomach & Adenocarcinoma & 3 & $\mathrm{Ib}$ & T2N0M0 & Malignant \\
\hline 34 & M & 52 & Stomach & Adenocarcinoma & 3 & $\mathrm{Ib}$ & T2N0M0 & Malignant \\
\hline 35 & $\mathrm{~F}$ & 54 & Stomach & Adenocarcinoma & 3 & IIIB & T4N1M0 & Malignant \\
\hline 36 & $\mathrm{~F}$ & 51 & Stomach & Adenocarcinoma & 3 & IIIa & T3N1M0 & Malignant \\
\hline 37 & M & 64 & Stomach & Carcinoma & - & II & T3N0M0 & Malignant \\
\hline 38 & M & 73 & Stomach & Adenocarcinoma & 3 & $\mathrm{Ib}$ & T2N0M0 & Malignant \\
\hline 39 & M & 62 & Stomach & Carcinoid & - & IIIa & T3N1M0 & Carcinoid \\
\hline 40 & M & 50 & Stomach & Adenocarcinoma & - & IIIa & T4N0M0 & Malignant \\
\hline
\end{tabular}

M, male; F, female; T, tumor; N, node; M, metastasis.

concentrated by centrifugation $\left(3,000 \mathrm{x} \mathrm{g} ; 4^{\circ} \mathrm{C} ; 45 \mathrm{~min}\right)$ with an Amicon ${ }^{\circledR}$ centrifugal filter (EMD Millipore, Billerica, MA, USA). Protein concentration was determined using a 2-D Quant kit (GE Healthcare, Chicago, IL, USA), according to the manufacturer's instructions. A total of $100 \mu \mathrm{g}$ each protein sample was precipitated, denatured, cysteine blocked $\left(60^{\circ} \mathrm{C}\right.$; $1 \mathrm{~h}$; Sigma-Aldrich; Merck KGaA), and digested with sequencing-grade modified trypsin. Following the use of
iTRAQ Reagent-8PLEX mixed with the corresponding protein samples, the pooled proteins from the STMN-silenced AGS cells were labeled with tags 114/116, and the pooled proteins from AGS cells without STMN knockdown were labeled with tags 113/115. All labels were from the iTRAQ Reagent-8PLEX Multiplex kit (Sigma-Aldrich; Merck KGaA) and the manufacturer's protocol was followed. The labeled samples were pooled prior to analysis. 
Fractionation of peptides. The pooled iTRAQ-labeled samples were dissolved in $300 \mu 1$ 1\% Pharmalyte (GE Healthcare) and $8 \mathrm{M}$ urea, and applied to IPG gel strips (pH 3-10; GE Healthcare) at $30 \mathrm{~V}$ for $14 \mathrm{~h}\left(20^{\circ} \mathrm{C}\right)$. The peptides were electrofocused successively at $500 \mathrm{~V}$ for $1 \mathrm{~h}, 1,000 \mathrm{~V}$ for $1 \mathrm{~h}, 3,000 \mathrm{~V}$ for $1 \mathrm{~h}$ and $8,000 \mathrm{~V}$ for $8.5 \mathrm{~h}$ for a total of $68 \mathrm{kV} / \mathrm{h}$ on an IPGphor system (GE Healthcare). The strips were removed and sliced into 36 sections of 5-mm thickness. Peptides were extracted from the gel using a $0.1 \%$ formic acid and $2 \%$ acetonitrile solution. The fractions were purified and concentrated on a C18 Discovery DSC-18 SPE column (Sigma-Aldrich; Merck $\mathrm{KGaA}$ ). The purified fractions were lyophilized and stored at $-20^{\circ} \mathrm{C}$ prior to mass spectrometric analysis.

Mass spectrometry and database search. Mass spectrometry was performed using a Qstar Elite mass spectrometer coupled to a Dionex Ultimate 3000 liquid chromatography system (Dionex Corporation, Sunnyvale, CA, USA). The purified, labeled peptides were reconstituted in a solution containing $2 \%$ acetonitrile solution and $0.1 \%$ formic acid and injected into the mass spectrometer. A gradient series for each analysis was loaded on a C18-PepMap column $(2 \mu \mathrm{m} \times 1,000 \mu \mathrm{m}$ x $50 \mathrm{~mm}$; Dionex Corporation) at a flow rate of $0.3 \mu \mathrm{l} / \mathrm{min}$. The two most abundantly charged ions above 20 counts were selected for mass spectrometry. Dynamic exclusion criteria was set to $30 \mathrm{sec}$ with a $\pm 50 \mathrm{kDa}$ mass tolerance. Protein identification and quantification was performed using ProteinPilot v.2.0 (Thermo Fisher Scientific, Inc.). Mass spectrometry data were processed by searching the UniprotKB database (https://www. uniprot.org/help/uniprotkb/). Methane thiosulfate was set as a fixed cysteine modification. Protein identification was based on selection thresholds of ProtScore $>1.3$ or ProtScore $<0.77$, and false discovery rate P-values $<0.05$. The PANTHER Classification System (www.pantherdb.org) was utilized to group the DEPs according to their biological processes and molecular functions.

$R N A$ extraction and $R T-q P C R$. Total RNA of AGS was extracted using TRIzol reagent (Invitrogen; Thermo Fisher Scientific, Inc.), according to the manufacturer's protocol. First-strand cDNA was synthesized from $2 \mu \mathrm{g}$ total RNA using a Reverse Transcription kit (Thermo Fisher Scientific, Inc.) according to the manufacturer's protocol. In order to determine the relative level of cDNA in the reverse transcribed samples, a SYBR Fast qPCR kit (Kapa Biosystems; Roche Diagnostics, Basel, Switzerland) was used to perform qPCR using the following primers: STMN, forward 5'-AGAACCGAGAGG CACAAATGGC-3' and reverse 5'-TCTCGTCAGCAGGGT CTTTGGA-3'; actin, forward 5'-CACCATTGGCAATGA GCGGTTC-3' and reverse 5'-AGGTCTTTGCGGATGTCC ACGT-3'.

The Kapa SYBR Fast qPCR kit was also used to perform qPCR with primers (Invitrogen; Thermo Fisher Scientific, Inc.) for APOE (NM_000041), forward 5'-GGGTCGCTTTTG GGATTACCTG-3' and reverse 5'-CAACTCCTTCATGGT CTCGTCC-3'; HSP90 (NM_005348), forward 5'-TCTGCC TCTGGTGATGAGATGG-3' and reverse 5'-CGTTCCACA AAGGCTGAGTTAGC-3'; FSCN1 (NM_003088), forward 5'-GACACCAAAAAGTGTGCCTTCCG-3' and reverse 5'-CAAACTTGCCATTGGACGCCCT-3'; CALM2
(NM_001743), forward 5'-AGTGCTGCAGAACTTCGCCA TG-3' and reverse 5'-CAAGGTCTTCACTTTGCTGTCA TC-3'; CTSD (NM_001909), forward 5'-GCAAACTGC TGGACATCGCTTG-3' and reverse 5'-GCCATAGTGGAT GTCAAACGAGG-3'; CST3 (NM_000099), forward 5'-CCT TCCATGACCAGCCACATCT-3' and reverse 5'-AGGCGT CCTGACAGGTGGATTT-3'; CDH17 (NM_004063), forward 5'-GGCAATGTGACTGCCAAGGATC-3' and reverse 5'-GCT TCTCTGTCCAATGGAGCCA-3'; MMP1 (NM_002421), forward 5'-ATGAAGCAGCCCAGATGTGGAG-3' and reverse 5'-TGGTCCACATCTGCTCTTGGCA-3'; CLU (NM_001831), forward 5'-TGCGGATGAAGGACCAGT GTGA-3' andreverse 5'-TTTCCTGGTCAACCTCTCAGCG-3'; MAPK1 (NM_002745), forward 5'-ACACCAACCTCTCGT ACATCGG-3' and reverse 5'-TGGCAGTAGGTCTGGTGC TCAA-3'; LGALS1 (NM_002305), forward 5'-AGCAGCGG GAGGCTGTCTTTC-3' and reverse 5'-ATCCATCTGGCA GCTTGACGGT-3'; PARK7 (NM_007262), forward 5'-GTC CTACTGCTCTGTTGGCTCA-3' and reverse 5'-CCACAC GATTCTCAGAGTAGGTG-3'; BSG (NM_001728), forward 5'-GGCTGTGAAGTCGTCAGAACAC-3' and reverse 5'-AC CTGCTCTCGGAGCCGTTCA-3'; CD9 (NM_001769), forward 5'-TCGCCATTGAAATAGCTGCGGC-3' and reverse 5'-CGCATAGTGGATGGCTTTCAGC-3'; SDCBP2 (NM_080489), forward 5'-AGTCCAGGCAACAGCCATT TCC-3' and reverse 5'-AAGCAGGCTCTCCTGGACTTCT-3'; CST4 (NM_001899), forward 5'-TGTGCCTTCCATGAA CAGCCAG-3' and reverse 5'-CCTAGGCTTCTTGACACC TGGA-3'; PFN1 (NM_005022), forward 5'-CATCGTGGG CTACAAGGACTCG-3' and reverse 5'-CCAAGTGTCAGC CCATTCACGT-3'; CACYBP (NM_014412), forward 5'-CTG CTGTGGTTGCTCCCATTAC-3' and reverse 5'-CACCTG CACATTCTCAGTGGGA-3'; GSTM5 (NM_000851), forward 5'-CACATGGAGCTGGTCAGACTGT-3' and reverse 5'-CT TGTCTCCT GCA A ACCATGGC-3'; COTL1 (NM_021149), forward 5'-AAATATGACGGCTCCACCATC GT-3' and reverse 5'-TGGACCTCTTGCTCATGGCATC-3'; COL4A2 (NM_001846), forward 5'-GGATAACAGGCGTG ACTGGAGT-3' and reverse 5'-CTTTGCCACCAGGCAGTC CAAT-3'; and CTSH (NM_004390), forward 5'-TACCTTCGA GGTACTGGTCCCT-3' and reverse 5'-GGTGGAGAAAGT CCAGCAACTG-3'. qPCR reaction was performed according to the instructions included in the Kapa SYBR Fast qPCR kit. Data were normalized to actin levels in all samples, and qPCR was carried out at $94^{\circ} \mathrm{C}$ for $60 \mathrm{sec}, 37^{\circ} \mathrm{C}$ for $60 \mathrm{sec}$, and at $72^{\circ} \mathrm{C}$ for $120 \mathrm{sec}$, for $25-30$ cycles in total. Quantification of gene expression was calculated using the $2^{-\Delta \Delta \mathrm{Cq}}$ method (15). RT-PCR analyses were conducted in triplicate.

Western blot analysis. GC cells were lysed with lysis buffer containing $1 \mathrm{mM}$ EDTA (pH 8.0), 0.5\% IGEPAL, $50 \mathrm{mM}$, $\mathrm{pH} 7.5$ Tris- $\mathrm{HCl}, 50 \mathrm{mM}$ sodium fluoride, $150 \mathrm{mM} \mathrm{NaCl}$, $1 \mathrm{mM}$ sodium orthovanadate, $0.5 \%$ Triton $\mathrm{X}-100$ and protease inhibitors. The concentration of extracted proteins was determined via an Enhanced BCA Protein Assay kit (Beyotime Institute of Biotechnology, Haimen, China). Approximately $30 \mu \mathrm{g}$ protein specimens were separated by $10 \%$ SDS-PAGE and transferred to polyvinylidene difluoride membranes. The membranes were blocked with $5 \%$ skimmed milk in TBS-Tween-20 buffer (TBST; pH 7.6; 0.5\% Tween-20) for 


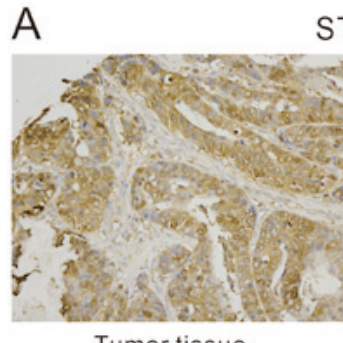

STMN

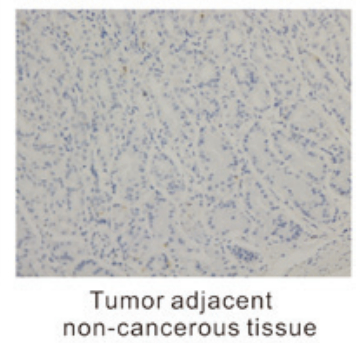

B

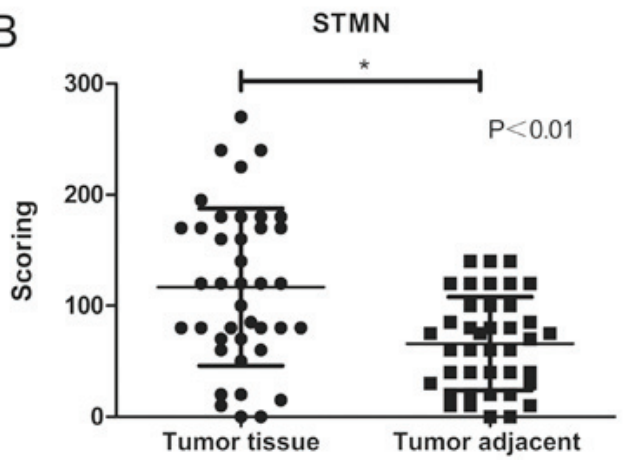

Figure 1. IHC assay for STMN. (A) Representative IHC images of STMN in GC tumor tissue and adjacent non-cancerous gastric tissue (magnification, $\mathrm{x} 200$ ). (B) Corresponding IHC score values of STMN were significantly higher in tumor tissues than in non-tumor adjacent tissues. " $\mathrm{P}<0.001$. IHC, immunohistochemistry; STMN, stathmin.

$1 \mathrm{~h}$ at room temperature. The membranes were incubated with monoclonal antibodies against STMN (1:300), sCLU $(1: 2,000)$, CST3 $(1: 4,000)$, CTSD $(1: 2,000)$, MMP9 $(1: 1,000)$, MMP1 (1:1,000), STAT3 (1:2,000), p-STAT3 $(1: 2,000)$, AKT (1:500), p-AKT (1:500), CDK1 (1:500), SOD1 $(1: 1,000)$, FSCN $(1: 1,000)$, CDH17 (1:1,000), APOE $(1: 2,000)$ and Hsp90 (1:500), overnight at $4^{\circ} \mathrm{C}$. The membranes were washed thrice with TBST and incubated with a horseradish peroxidase-conjugated goat anti-mouse (sc-2039) immunoglobulin G (IgG) or goat anti-rabbit (sc-2040) IgG antibody (both 1:5,000; Santa Cruz Biotechnology, Inc., Dallas, TX, USA) for $1 \mathrm{~h}$ at room temperature. The membranes were washed thrice with TBST and visualized with an ECL detection system (Bio-Rad Laboratories, Inc.). Western blot analyses were performed in triplicate using Image Lab software (Bio-Rad Laboratories, Inc).

Transwell and wound-healing assays. Wound-healing, and cell migration and invasion assays were conducted 2 days following transfection. The wound-healing assay was performed in 6-well plates with $60 \%$ cells. When the cultured cells reached $100 \%$ confluence, a sterile p200 pipette tip was used to incise a wound in the cell monolayer and the debris was removed by gently washing with PBS. Images of the scratches were captured at 0 and $24 \mathrm{~h}$ under $\left(37^{\circ} \mathrm{C}\right)$ a phase contrast microscope (magnification, $\mathrm{x} 20$ ). The capacity of cell migration was determined by the extent of gap closure.

The Transwell migration and invasion assays were performed using a 24-well Cell Migration and Invasion Assay kit (Cell Biolabs, Inc., San Diego, CA, USA). In brief, following transfection with STMN or control siRNA, AGS cells starved for $24 \mathrm{~h}\left(37^{\circ} \mathrm{C}\right)$, and harvested and resuspended

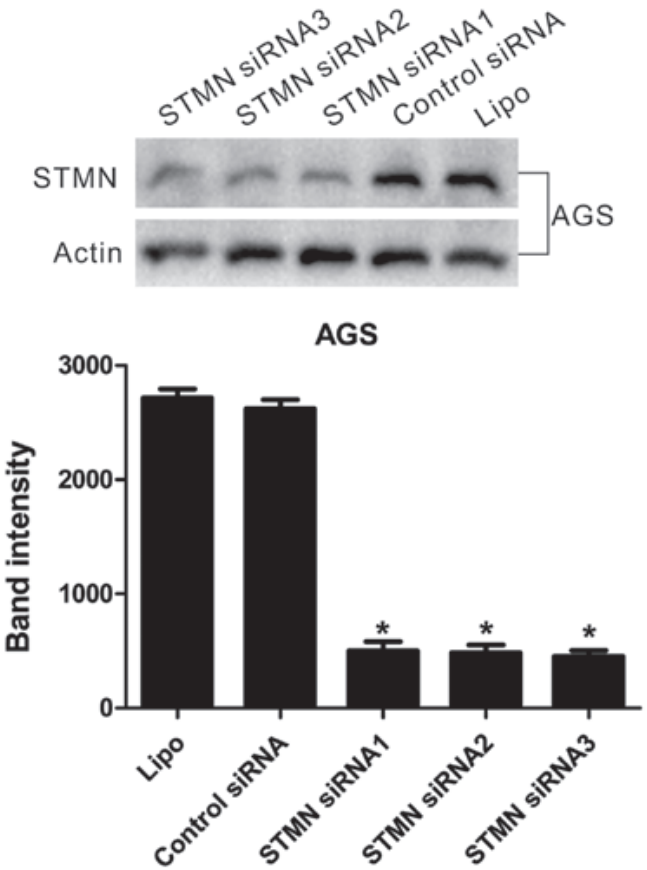

Figure 2. Western blot analysis demonstrated that silencing of STMN by three different STMN-specific siRNA sequences significantly reduced STMN protein levels in lysates of AGS cells, compared with control siRNA and Lipo. ${ }^{*} \mathrm{P}<0.001$ vs. control. STMN, stathmin; siRNA, small interfering RNA; Lipo, Lipofectamine 2000.

in serum-free media, according to the manufacturer's protocol. The lower chambers were filled with $500 \mu \mathrm{l}$ media (RPMI-1640 plus $10 \%$ FBS), and $\sim 3 \times 10^{5}$ cells $/ 300 \mu 1$ media were loaded into the upper chamber, with or without Matrigel. The migrating/invading cells on the bottom of the filters were stained, fixed and extracted, according to the manufacturer's instructions, and the optical density was measured at $560 \mathrm{~nm}$ at 12 or $24 \mathrm{~h}$ following seeding. The determination of STMN downregulation was made via western blotting analysis, as detailed above. All experiments were performed in triplicate.

Cell proliferation assay and flow cytometry. Cell proliferation was analyzed using an MTT assay. Briefly, AGS cells were seeded in 96 -well plates at a density of $1.5 \times 10^{3}$ cells/well. Cells were transfected with STMN siRNA or control siRNA, as detailed above, and cultured in DMEM media supplemented with $10 \%$ FBS for $0,24,48,72$ and $96 \mathrm{~h}$ at $37^{\circ} \mathrm{C}$. The cells were then incubated with $20 \mu$ l MTT (Sigma-Aldrich; Merck $\mathrm{KGaA}$ ) at $37^{\circ} \mathrm{C}$ for $4 \mathrm{~h}$. The MTT substrate was dissolved in $200 \mu$ l dimethyl sulfoxide (Sigma-Aldrich; Merck KGaA) for $5 \mathrm{~min}$. Absorbance at $570 \mathrm{~nm}$ was then measured. All experiments were performed in triplicate.

Cell apoptosis and cell cycle tests were analyzed by flow cytometry (FACSCanto II; Becton, Dickinson and Company, Franklin, Lakes, NJ, USA) after AGS cell were stained with an Annexin V-FLUOS Staining kit (Sigma-Aldrich; Merck $\mathrm{KGaA}$ ) and propidium iodide and treated with STMN-specific siRNA and negative control siRNA. All assays were performed independently at least three times.

Statistical analysis. All experiments were performed at least in triplicate. Continuous variables are presented as 

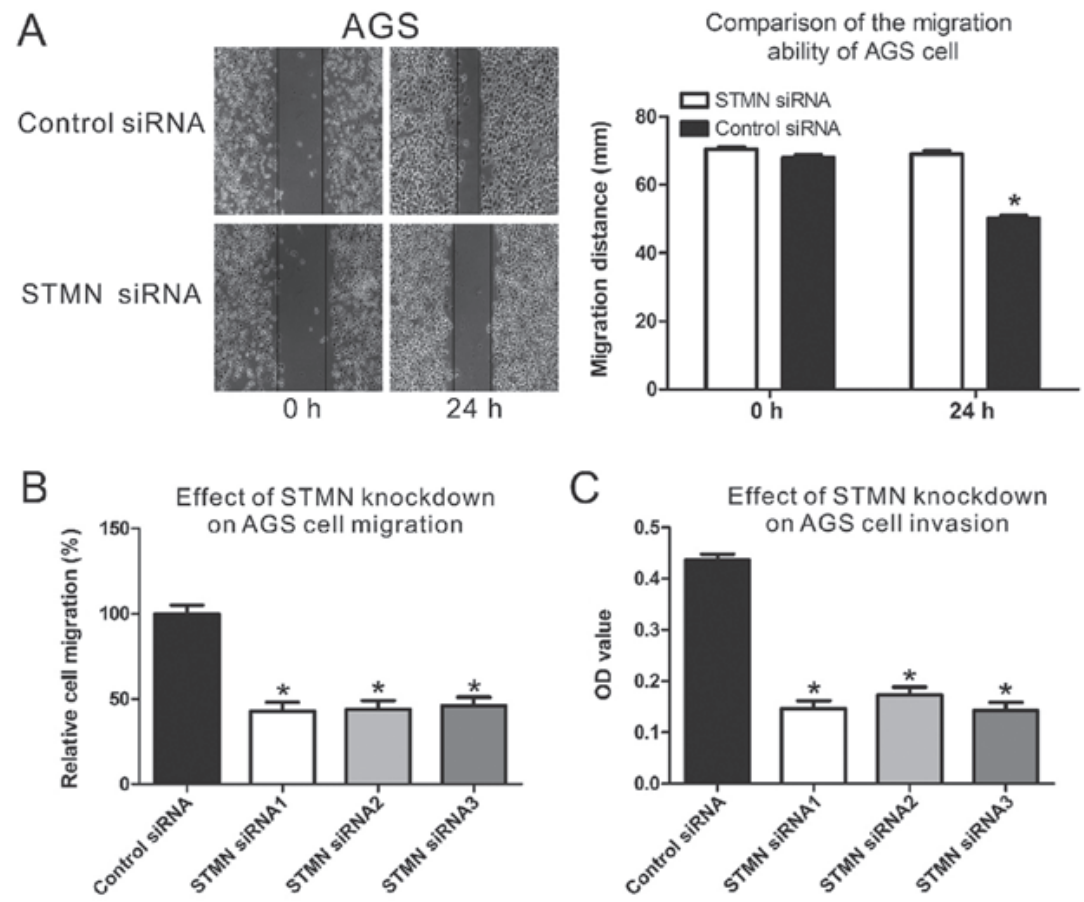

Figure 3. STMN has a critical role in GC cell migration and invasion. (A) Comparison of the migration ability of GC cell lines with and without STMN knockdown (siRNA2) by wound healing assays. (B) Differences in the migration capability of AGS cells between STMN knockdown and the controls, determined by Transwell assays. (C) Differences in the invasive capability of AGS cells between STMN knockdown and the controls, determined by Transwell assays. ${ }^{*} \mathrm{P}<0.05$ vs. control. STMN, stathmin; GC, gastric cancer; siRNA, small interfering RNA; OD, optical density.

the mean \pm standard deviation. All statistical analyses were performed using SPSS 20.0 software (IBM Corp., Armonk, NY, USA). Differences between two groups were analyzed by paired or unpaired Student's t-tests. One-way analysis of variance was used to compare multiple groups, and when appropriate, it was followed by Fisher's least significant difference post hoc test. $\mathrm{P}<0.05$ was considered to indicate a statistically significant difference.

\section{Results}

Differential expression of STMN in tissues. IHC was performed on tissue microarrays of GC and non-cancerous tissues to identify the differential expression of STMN. All 40 stomach neoplasm samples exhibited strong staining, whereas the 40 non-cancerous samples exhibited no staining. The results revealed that STMN was expressed at greater levels in GC samples than in non-cancerous samples (Fig. 1A). The IHC score was used to evaluate the different expression of STMN in GC and non-cancerous tissues. IHC score values of STMN were significantly higher in the GC tissue group than in the adjacent normal tissues group (Fig. 1B), Furthermore, paired Student's t-test analysis denoted that the difference in STMN expression between the stomach neoplasm tissues and the adjacent normal tissues was statistically significant $(\mathrm{P}<0.001)$.

Effect of STMN on cell biological processes in GC. As upregulation of STMN in GC samples was demonstrated in the IHC results, the association of STMN with biological processes was validated. RNA interference was used to inhibit STMN expression in AGS GC cells. The cells were transfected with three STMN-specific siRNA sequences and control siRNA.
Western blot analysis demonstrated that the STMN-specific siRNA significantly downregulated the expression of STMN in the AGS GC cell line ( $\mathrm{P}<0.001$; Fig. 2).

The results of the wound-healing assay demonstrated that siRNA-mediated silencing of STMN significantly decreased the ability of transfected cells to close scratch wounds in the AGS cells $(\mathrm{P}<0.05$; Fig. $3 \mathrm{~A})$. The migration assay demonstrated that downregulated expression of STMN weakened the migration ability of AGS cells by 45-48\%, compared with the control group $(\mathrm{P}<0.05$; Fig. 3B). The invasion assay confirmed that downregulation of STMN expression inhibited the invasive capacity of AGS cells by $60 \%$, in comparison with control siRNA ( $\mathrm{P}<0.05$; Fig. 3C). These results indicated that STMN has a crucial role in GC metastasis and invasiveness.

In order to determine whether the anti-apoptotic, proliferation and cell cycle progression properties of GC were due to upregulation of STMN, these capacities were assayed in cell lines with and without STMN knockdown. STMN silencing resulted in a $\times 3.9$ increase in apoptosis in AGS cells, compared with controls ( $\mathrm{P}<0.05$; Fig. 4A and B). Knockdown of STMN also increased S-phase cell cycle arrest by $50 \%$ in the AGS cell line, compared with the siRNA control $(\mathrm{P}<0.05$; Fig. 4C and D). The MTT assay demonstrated that proliferation of STMN-silenced AGS cells was decreased compared with the control cells $(\mathrm{P}<0.05$; Fig. 4E). Together, these results indicated that STMN promotes invasion and metastasis, proliferation and anti-apoptotic behavior in stomach neoplasm.

Analysis of iTRAQ data of DEPS. In order to investigate the mechanism by which STMN influences biological functions in GC cells, the iTRAQ proteomics approach was employed 

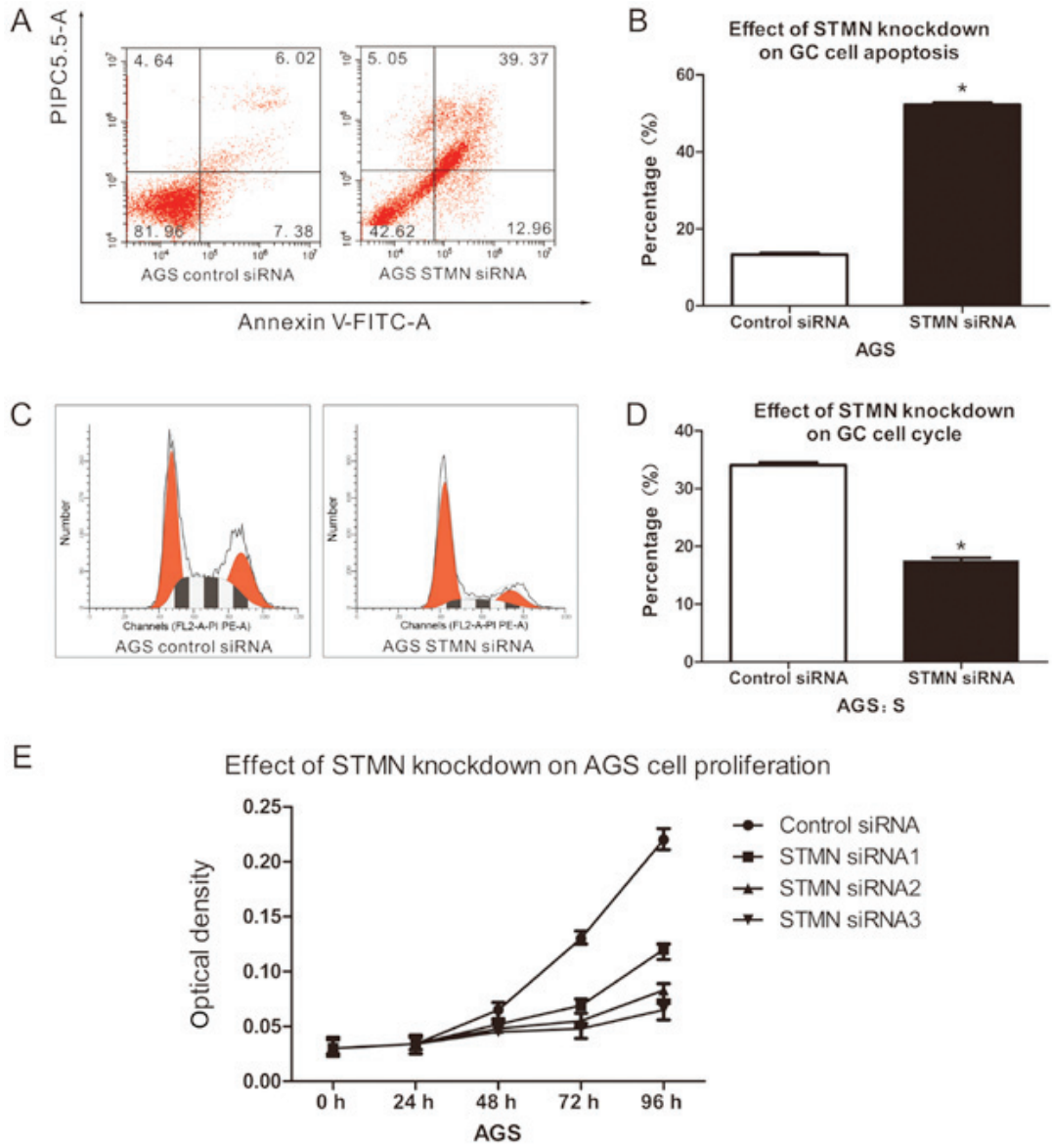

Figure 4. Proliferative and anti-apoptotic effects of GC cells are associated with the overexpression of STMN. (A and B) The STMN-silenced cells and controls were stained with Annexin V-FITC and PI, and then subjected to flow cytometry. Percentage of cells in apoptosis is presented on the graphs. (C and D) The STMN-silenced STMN knockdown and controls were stained with PI and subjected to cell cycle analysis by flow cytometry. The percentage of cells in each phase of the cell cycle is graphically presented and illustrated as a graph. (E) Proliferation was significantly inhibited in AGS cells following silencing STMN, compared with the controls. "P<0.05 vs. control. GC, gastric cancer; STMN, stathmin; FITC, fluorescein isothiocyanate; PI, propidium iodide; siRNA, small interfering RNA.

to discern differentially expressed proteins. Fig. 5 presents the flow chart of the iTRAQ proteomics methodology. iTRAQ-based MS was performed on proteins isolated from AGS cells following siRNA-mediated STMN knockdown and from un-silenced control cells. In order to improve the reliability and enhance the range of protein identification, specimens were iTRAQ-labeled in duplicate. The ratios of 114:113 and 116:115 identified the differential protein expression in AGS cells. A ProteinPilot-based database search was performed, with thresholds set to achieve $95 \%$ confidence at a $5 \%$ false discovery rate, and hundreds of proteins were identified. Conforming to commonly accepted iTRAQ-based MS conventions (16), proteins with ratios of $<0.77(1 / 1.3)$ or $>1.3(1.3 / 1)$ were classified as downregulated or upregulated, respectively. The technical variation of data from duplicate experiments was $<30 \%$. A total of 96 proteins were identified with a confidence of $95 \%$, of which 45 were significantly upregulated and 51 downregulated. Table II presents a list of 31 proteins representative of the total identified proteins.

Cellular and molecular functional annotation of the DEPs. The 96 DEPs belonged to 21 protein classes, 13 biological processes and 7 molecular functions (Fig. 6). The results demonstrated that 'catalytic activity' and 'binding' were the most common molecular functions and that 'metabolic process' was the most common biological process.

Validation of differentially expressed proteins identified by $i T R A Q$. RT-qPCR and western blot analyses were performed to validate the differentially expressed proteins identified by iTRAQ. RT-PCR determined the mRNA expression levels of PARK7, BSG, CD9, SDCBP2, CST4, APOE, HSP90, FSCN1, CALM2, PFN1, CACYBP, GSTM5, COTL1, CTSD, CST3, CDH17, LGALS1, sCLU, COL4A2, CTSH, MAPK1 and MMP1. Actin was used as the control. The mRNA levels were consistent with the results obtained via iTRAQ. Following knockdown of STMN, the mRNA expression levels of BSG, FSCN, PFN1, CACYBP, GSTM5, COTL1, COL4A2, CTSH and MAPK were increased, whereas CTSD, CST3, CDH17, LGALS1, sCLU, MMP1, PARK7, CD9, SDCBP2, CST4, APOE, HSP90 and CALM2 were decreased (P<0.05; Fig. 7A). Western blot analysis was utilized to quantify the expression levels of the identified proteins that were identified by iTRAQ and RT-qPCR. The levels of the extracellular sCLU, CST3, CTSD, MMP1, MMP9 and the intracellular CDK1, CTSD, HSP90 and SOD1 corresponded with the results in the above iTRAQ and RT-qPCR analysis ( $<<0.05$; Fig. 7B). The expression levels of CALM2, APOE and LGALS1 were too low to be 


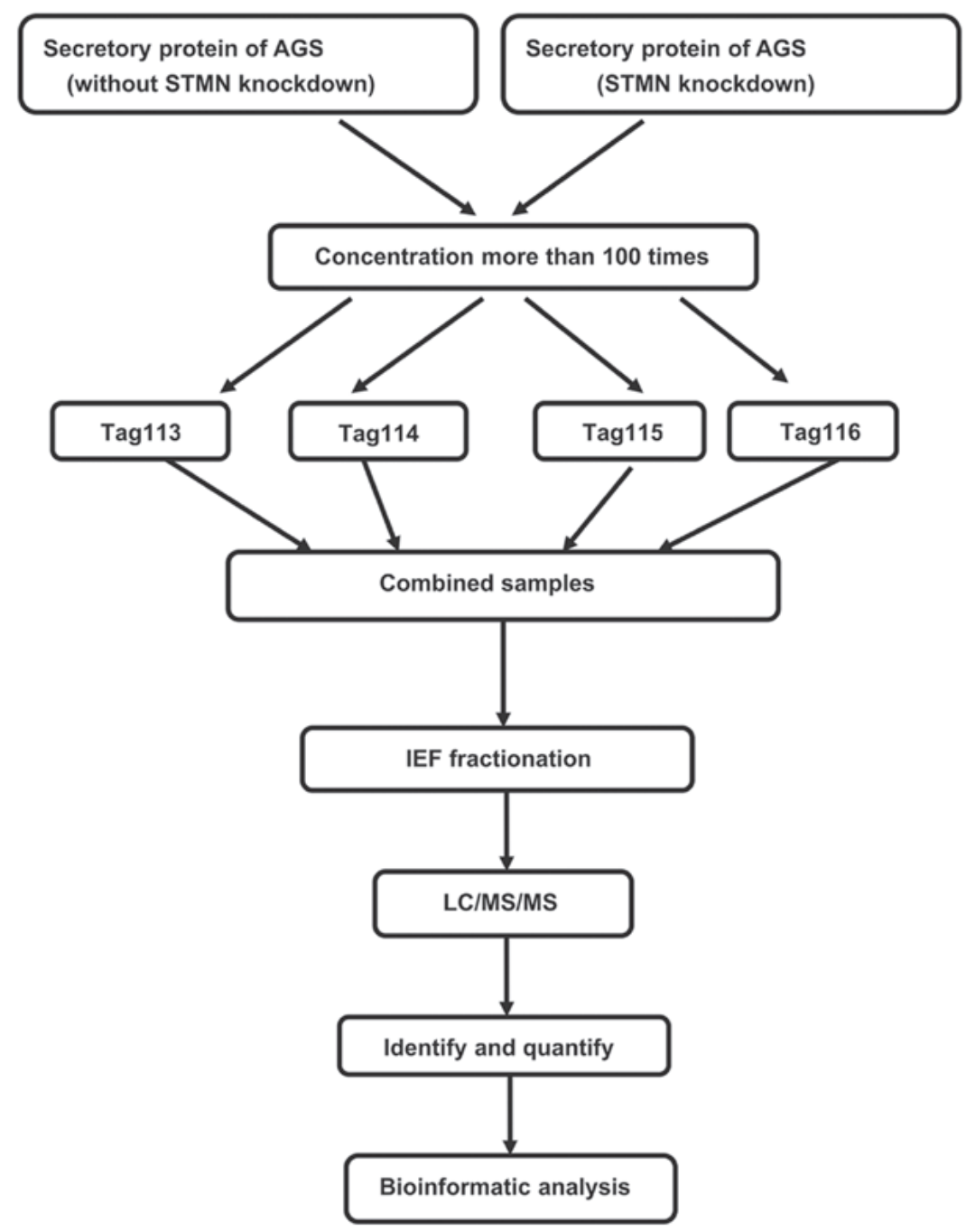

Figure 5. Flow chart of the isobaric tags for relative and absolute quantitation-based MS proteomics approach used in the present study. MS, mass spectrometry; STMN, stathmin. IEF, isoelectric focusing; LC, liquid chromatography.

detected by western blot analysis and the differential expression of FSCN, CTSH and MAPK were deemed to be without clinical significance.

STMN promotes the development of GC via different pathways. As has been confirmed by extensive studies, activated AKT and STAT3 signaling is closely associated with the biological functions of many tumors, also associated with GC (17-26). Western blot analyses demonstrated that the activity of AKT and STAT3 signaling was decreased following inhibition of STMN expression $(\mathrm{P}<0.05$; Fig. 8). These results revealed that STMN promotes the development of GC via different pathways.

\section{Discussion}

GC is the third most common cause of cancer-related mortality worldwide, and has attracted much attention due to its relatively high rates of incidence and mortality (3). Although surgical resection and chemotherapy are the mainstream methods of treating this malignancy, patients suffering from advanced stage GC have poor prognoses and high mortality rates. The vast majority of patients already have metastasis by the time a diagnosis is made (27). Previous studies have confirmed that the 5-year survival rate of tumors is substantially reduced for patients with metastases $(2,28)$. Metastasis and recurrence are major obstacles to the improvement of survival rates and quality of life in GC patients. Therefore, investigations into the molecular mechanisms involved in GC progression are necessary and may provide insights leading to improved diagnosis and therapeutic approaches.

STMN is a microtubule regulating protein that has a critical role in the aggregation and depolymerization of mitotic spindles. The critical functions of STMN in cancer cells have been investigated and it is known to participate in regulating many cellular functions of gastrointestinal malignancies (14). STMN is frequently overexpressed in many human cancers including lung (29), bladder (30), endometrial (31) and oral cancer (32).

Furthermore, STMN expression has been demonstrated to be significantly associated with tumor cell biological functions. For instance, STMN is associated with the proliferation, differentiation and metastasis of cancers (33). High levels of STMN expression are required for maintaining high proliferation rates in tumor cells (34). A previous study also concluded that high STMN expression was significantly associated with 
Table II. Differentially expressed proteins in supernatant of AGS cells: STMN knockdown vs. control.

\begin{tabular}{|c|c|c|c|c|c|}
\hline Accession & $\begin{array}{l}\text { Gene } \\
\text { symbol }\end{array}$ & Protein name & $\begin{array}{l}\text { Peptides } \\
(95 \%)\end{array}$ & $\begin{array}{c}\text { AGS STMN, } \\
\text { knockdown } \\
\text { 114:control } 113\end{array}$ & P-value \\
\hline splQ99497IPARK7_HUMAN & PARK7 & Protein DJ-1 & 9 & 0.73154 & 0.0104 \\
\hline trlQ54A51IQ54A51_HUMAN & BSG & Basigin & 5 & 0.729301 & 0.0104 \\
\hline trlG8JLH6IG8JLH6_HUMAN & CD9 & Tetraspanin & 3 & 0.514838 & 0.0052 \\
\hline splQ9H190|SDCB2_HUMAN & SDCBP2 & Syntenin-2 & 3 & 0.71116 & 0.0028 \\
\hline splP01036lCYTS_HUMAN & CST4 & Cystatin-S & 25 & 0.287784 & 0.0004 \\
\hline splP02649|APOE_HUMAN & APOE & Apolipoprotein E & 19 & 0.488746 & 0.0001 \\
\hline sp|P07339|CATD_HUMAN & CTSD & Cathepsin D & 39 & 0.629353 & 0.0006 \\
\hline splP01034|CYTC_HUMAN & CST3 & Cystatin-C & 30 & 0.457414 & 0.0020 \\
\hline splQ12864|CAD17_HUMAN & $\mathrm{CDH} 17$ & Cadherin-17 & 22 & 0.499042 & 0.0069 \\
\hline trlA8K690|A8K690_HUMAN & HSP90 & Hsp90 & 18 & 0.739335 & 0.0407 \\
\hline sp|P10909|CLUS_HUMAN & CLU & Clusterin & 19 & 0.594053 & 0.0002 \\
\hline splQ14764IMVP_HUMAN & MVP & Major vault protein & 18 & 0.706437 & 0.0005 \\
\hline sp|P08572|CO4A2_HUMAN & COL4A2 & Collagen $\alpha$-2(IV) chain & 17 & 1.038458 & 0.0007 \\
\hline sp|P09382|LEG1_HUMAN & LGALS1 & Galectin-1 & 15 & 0.687828 & 0.0039 \\
\hline trlQ6IBC3IQ6IBC3_HUMAN & CTSH & CTSH protein & 14 & 0.874563 & 0.0387 \\
\hline trlQ53G96IQ53G96_HUMAN & MMP1 & $\begin{array}{l}\text { Matrix metalloproteinase-1 } \\
\text { preproprotein }\end{array}$ & 10 & 0.662887 & 0.0049 \\
\hline sp|P14780|MMP9_HUMAN & MMP9 & Matrix metalloproteinase-9 & 3 & 0.57889 & 0.0030 \\
\hline trlJ3QR44|J3QR44_HUMAN & CDK1 & Cyclin-dependent kinase 1 & 3 & 0.577492 & 0.0076 \\
\hline splQ9Y3F4ISTRAP_HUMAN & $\mathrm{AKT}$ & $\begin{array}{l}\text { Serine-threonine kinase } \\
\text { receptor-associated protein }\end{array}$ & 7 & 0.621259 & 0.0092 \\
\hline trlB5BTZ6IB5BTZ6_HUMAN & STAT3 & $\begin{array}{l}\text { Signal transducer and } \\
\text { activator of transcription }\end{array}$ & 9 & 0.71708 & 0.0261 \\
\hline splQ13347|EIF3I_HUMAN & EIF3I & $\begin{array}{l}\text { Eukaryotic translation } \\
\text { initiation factor } 3 \text { subunit I }\end{array}$ & 3 & 0.807284 & 0.0469 \\
\hline trlB3KQF4|B3KQF4_HUMAN & $\begin{array}{l}\text { Metalloproteinase } \\
\text { inhibitor } 1\end{array}$ & $\begin{array}{l}\text { Metalloproteinase } \\
\text { inhibitor } 1\end{array}$ & 6 & 0.536465 & 0.0046 \\
\hline sp|P02647|APOA1_HUMAN & APOA1 & Apolipoprotein A-I & 6 & 0.668486 & 0.0140 \\
\hline trlB5BU83|B5BU83_HUMAN & STMN1 & Stathmin & 4 & 0.461021 & 0.0020 \\
\hline trlB3KTA3|B3KTA3_HUMAN & Fascin & Fascin & 16 & 1.283847 & 0.0150 \\
\hline trlH0Y7A7IH0Y7A7_HUMAN & CALM2 & Calmodulin & 35 & 1.389 & 0.0040 \\
\hline splP07737|PROF1_HUMAN & PFN1 & Profilin-1 & 35 & 1.266123 & 0.0080 \\
\hline trlQ6NVY0|Q6NVY0_HUMAN & CACYBP & Calcyclin binding protein & 10 & 1.202297 & 0.0260 \\
\hline splP46439|GSTM5_HUMAN & GSTM5 & Glutathione S-transferase $\mu 5$ & 5 & 1.757358 & 0.0005 \\
\hline splQ14019|COTL1_HUMAN & COTL1 & Coactosin-like protein & 6 & 1.835 & 0.0014 \\
\hline splP00441ISODC_HUMAN & SOD1 & Superoxide dismutase & 9 & 1.305398 & 0.0023 \\
\hline
\end{tabular}

STMN, stathmin.

tumor invasion and TNM clinical classification in esophageal carcinoma (9). STMN has been demonstrated to be an oncogene in many kinds of tumors, which promotes proliferation, invasion and metastasis in a variety of tumors $(35,36)$. In the present study, the results of the comparison of STMN expression between GC tissues and adjacent non-cancerous tissues were in accordance with previous research. It was demonstrated that STMN could significantly promote tumor cell migration, invasion and proliferation and had an anti-apoptotic effect in GC cells. These effects may be because the microtubule-destabilizing activity of STMN interferes with microtubule dynamics. The findings suggested that STMN may be a pivotal factor contributing to the formation and progression of GC and that STMN could be considered a valuable prognostic indicator and therapeutic target in patients with GC.

Using the iTRAQ proteomics methodology, 96 DEPs were identified in GC samples, the majority of which were involved in metabolic and cellular processes. A number of them, including HSP90, CTSD, CST3, sCLU, MMP1, SOD1, CDK1 and MMP9 were confirmed using RT-qPCR and western blot analyses. Based on protein classes, biological processes and molecular 


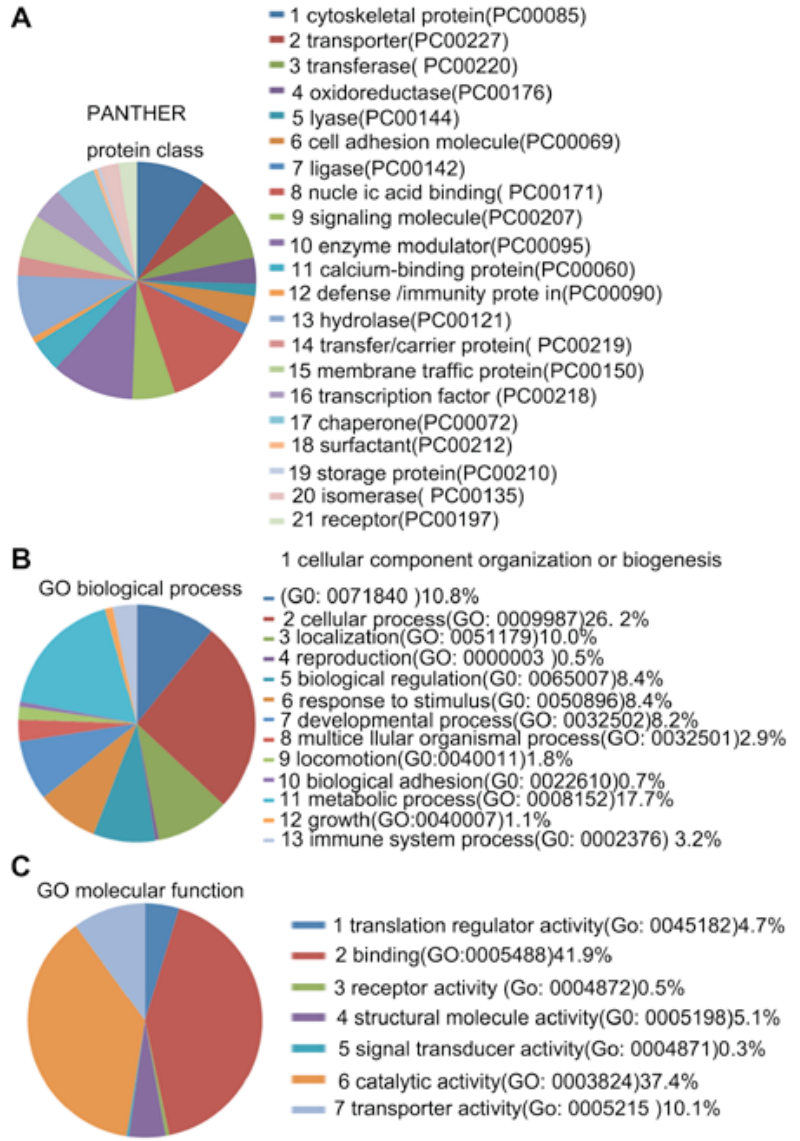

Figure 6. Classification of proteins observed to be differentially expressed in gastric cancer cells. Proteins were categorized by (A) protein class, (B) biological process, and (C) molecular function via the PANTHER Classification System (www.pantherdb.org/). PANTHER, Protein Analysis through Evolutionary Relationships.

functions, the DEPs were further classified into different types and several vital proteins that are responsible for the apparent differences following silencing STMN were evaluated.

CLU is a highly conserved glycoprotein with ubiquitous tissue distribution. It appears to have two main isoforms with vastly different functions: Secretory CLU (sCLU) and intracellular CLU (nCLU). sCLU represents the major product of the CLU gene $(37,38)$. Recently, a number of studies have demonstrated that expression of sCLU is significantly higher in many types of cancer, compared with adjacent non-cancerous tissue (37-40). Overexpression of sCLU has been identified to be associated with tumor invasion, metastasis, anti-apoptotsis, cell proliferation and survival in neoplasm of the human bladder and in renal, liver, prostate, breast, lung and gastrointestinal malignant tumors $(37,41)$. For example, overexpression of clusterin correlates with tumor progression and metastasis in GC (40). The present results revealed that inhibition of STMN significantly downregulated sCLU protein expression in GC. These findings suggest that STMN promotes GC cell invasion, metastasis, anti-apoptotsis, cell proliferation, survival ability by regulating the expression of sCLU.

Signaling pathways involved in interactions with sCLU were further investigated. A number of previous studies have verified that numerous intracellular and extracellular proteins promote tumor cell biological functions through activation of the AKT pathway via upregulation of sCLU. A recent study
A

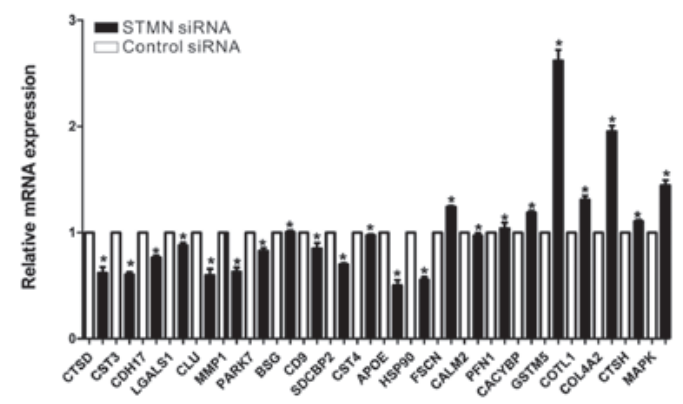

B
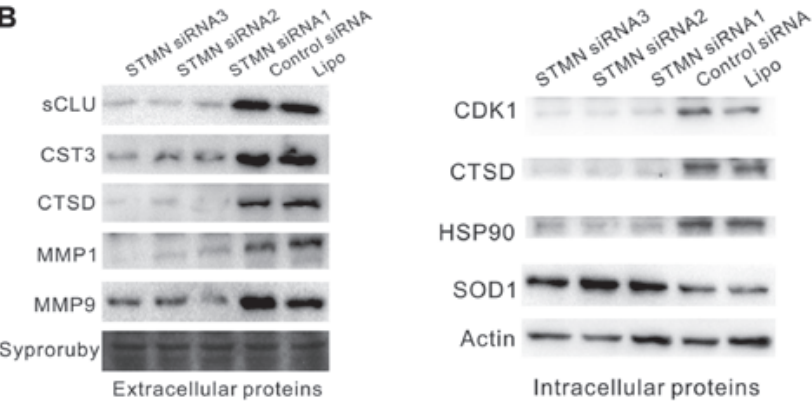

CTSD
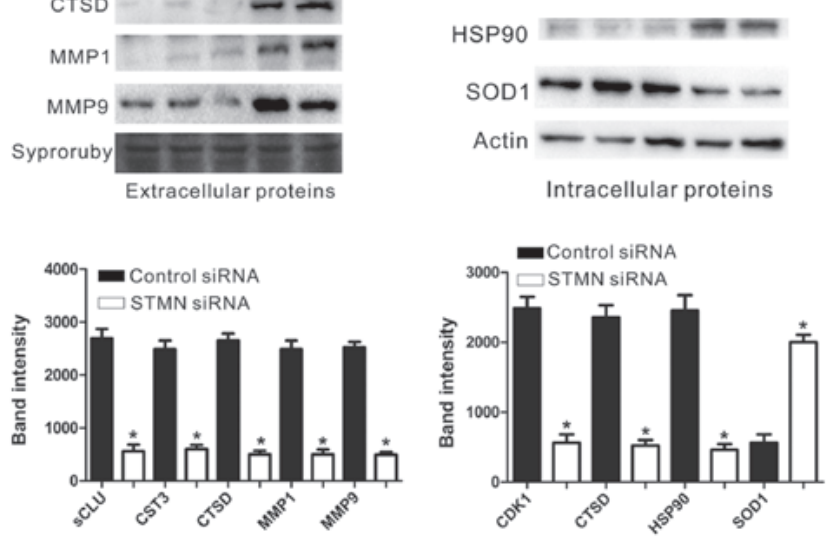

Figure 7. Validation of DEPs. (A) Reverse transcription-quantitative polymerase chain reaction detected the relative mRNA expression levels of a number of DEPs, as normalized to actin. (B) A representative western blot analysis for sCLU, CST3, CTSD, MMP1, MMP9, CDK1, HSP90 and SOD1 expression in the experimental and control groups. ${ }^{*} \mathrm{P}<0.05$ vs. control. DEP, differentially expressed protein; sCLU, secretory clusterin; CST3, cystatin-C; CTSD, cathepsin D; MMP, matrix metalloproteinase; CDK, cyclin-dependent kinase; HSP90, heat shock protein 90; SOD, superoxide dismutase.

reported that CLU can promote HCC metastasis through AKT-MMP13 signaling (42), and several studies have mentioned that CDK1, SOD1 and CTSD regulate tumor cell biological functions by influencing AKT signaling (43-47). In the present study, it was demonstrated that the expression of sCLU, CDK1, SOD1 and CTSD in the STMN-silenced group was downregulated, compared with the control group. The AKT signaling pathway is believed to act downstream of sCLU. For example, the sCLU-AKT signaling pathway is responsible for cisplatin resistance in human lung cancer (48). Insulin-like growth factor-1 activates the P13K/AKT signaling pathway via upregulation of sCLU in lung carcinoma (49). Clusterin facilitates metastasis by eukaryotic translation initiation factor 3 subunit I (EIF3I)/AKT/MMP13 signaling in hepatocellular carcinoma (42). Previous studies confirmed that abnormal activation of the AKT signaling pathway was common in $\mathrm{GC}$, was associated with tumorigenesis of $\mathrm{GC}$, and promoted tumor migration and tumor aggressiveness in GC cells (17-21). According to the western blot analysis in the present study, the results demonstrated that the expression of sCLU and the phosphorylation level of the AKT protein in the AGS cells were markedly inhibited following knockdown of STMN. 

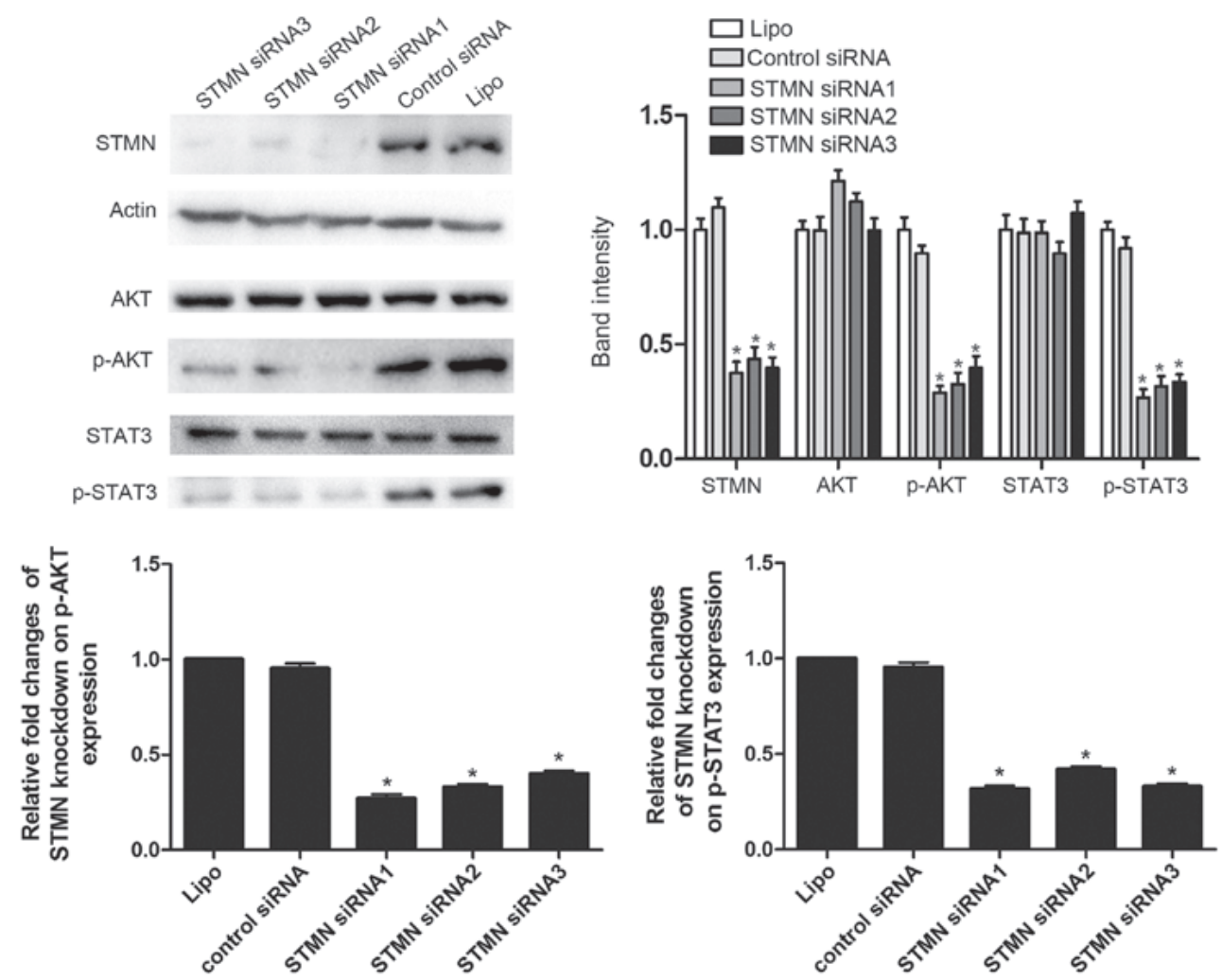

Figure 8. Western blot analysis of AKT, p-AKT, STAT3 and p-STAT3 in AGS cells with STMN-knockdown and controls. Relative fold changes of p-STAT3/ p-AKT expression analysis indicates significant reduction of p-AKT and p-STAT3 following STMN silencing. "P<0.05 vs. control. AKT, protein kinase B; p, phosphorylated; STAT, signal transducer and activation of transcription; STMN, stathmin; siRNA, small interfering RNA; Lipo, Lipofectamine 2000.

Our results demonstrated that, following STMN silencing, the expression levels of MMP9 and MMP1 were downregulated and sCLU expression decreased. MMPs are produced by various types of cancer cells. It has been reported that sCLU induces matrix metalloproteinase-9 expression via phosphoinositide 3-kinase/AKT/nuclear factor- $\mathrm{kB}$ pathways in monocytes/macrophages (50). This suggests that STMN activates the AKT-MMP9 signaling pathway to promote GC cell invasion, metastasis, anti-apoptotsis, cell proliferation and survival via upregulation of sCLU.

A previous study on hepatocellular carcinoma confirmed that overexpression of sCLU was accompanied by an upregulation in levels of the EIF3I protein and that sCLU may protect EIF3I from degradation. The sCLU-EIF3I complex may function as a cooperative unit in cancer cells (42). Wang et al (42) also reported that EIF3I could form a complex with AKT and lead to a constitutive activation of AKT signaling. AKT phosphorylation was significantly inhibited when EIF3I was silenced. These results suggest that sCLU forms a complex with EIF3I and prevents its degradation, leading to upregulation of AKT activity. Furthermore, according to iTRAQ results, the expression of EIF3I was obviously decreased in GC when STMN was silenced. In agreement with these analyses, the present findings reveal a potential mechanism in GC wherein STMN significantly regulates sCLU protein expression, and sCLU forms a complex with EIF3I to activate the AKT signaling pathway. This, in turn, promotes expression of MMP9 and leads to facilitated metastasis, invasion, anti-apoptosis and cell proliferation of GC cells.
Conversely, the results of ITRAQ and western blot analyses demonstrated that STMN-knockdown attenuated STAT3 activation in GC cells. Previous studies have demonstrated that the STAT3 signaling pathway acts downstream of STMN and that activated STAT3 upregulates MMP expression (51-54). STAT3, which is considered a point of convergence for numerous oncogenic signaling pathways, is constitutively activated in tumor cells and is known to promote cell proliferation and angiogenesis and serve a role in tumor avoidance of immune responses. Therefore, the proliferative and anti-apoptotic effects of STMN in GC are possibly associated with STAT3 signaling activation and concomitant expression of MMPs.

The present results also revealed that inhibition of STMN was accompanied by an abnormal regulation in the levels of CST3, CDK1, CTSD, SOD1 and HSP90 proteins. Previous studies reported the aberrant expression of these proteins in GC and that a number of them are associated with AKT signaling pathway activation, thus contributing to cell proliferation and metastasis (55-62). As such, the present findings suggested that STMN may promote the biological functions in GC by combined interactions with these intracellular and extracellular proteins.

In summary, the present study revealed several mechanisms by which STMN regulates GC tumor cells. Primarily, STMN significantly regulates sCLU protein expression and sCLU facilitates metastasis, invasion, anti-apoptosis and cell proliferation of GC cells via the EIF3I/AKT/MMP9 signaling pathway, Secondly, STMN is possibly associated with STAT3 signaling activation and overexpression of MMPs to influence the occurrence and development of GC. These results indicate that targeting STMN may be a rational strategy for suppressing 
the progression of GC. The present results suggest a potential molecular pathway of STMN mediating its influence on GC. Additional studies to verify the pathway identified in the present study and to demonstrate the conclusion in animal models are necessary to further elucidate the molecular mechanisms underlying the effect of STMN in GC. Furthermore, a drawback of the present study is that, generally, at least two cell lines should be used in a well-structured study, whereas only one GC cell line was used in the present study.

\section{Acknowledgments}

Not applicable.

\section{Funding}

The present study was supported by the National Natural Science Foundation of China (grant nos. 81171560, 30930082, 81171561, 30972584 and 81372399), the National Science and Technology Major Project of China (grant nos. 2008ZX10002-006, 2012ZX1002007001, 2011ZX09302005, 2012ZX09303001-001 and 2012ZX10002003) and the Capital's Funds for Health Improvement and Research (grant no. 2016-1-2112).

\section{Availability of data and materials}

Datasets included in the present study can be obtained from the corresponding author.

\section{Authors' contributions}

FS and XZ performed all experiments. HT, SS and JH performed a number of experiments. HR, HH and SP gave some critical suggestions to this project. FS and XZ analyzed data and wrote the manuscript. JW and YY were involved in the conception, design and final approval of manuscript. YY obtained financial support, and final approval of manuscript.

\section{Ethics approval and consent to participate}

All methods used in the present study were approved by the Ethics Committee of Chongqing Medical University (Chongqing, China), and all patients provided written informed consent prior to participation.

\section{Patient consent for publication}

All patients provided written informed consent prior to participation.

\section{Competing interests}

The authors declare that they have no competing interests.

\section{References}

1. Ferlay J, Soerjomataram I, Dikshit R, Eser S, Mathers C, Rebelo M, Parkin DM, Forman D and Bray F: Cancer incidence and mortality worldwide: Sources, methods and major patterns in GLOBOCAN 2012. Int J Cancer 136: E359-E386, 2015.
2. Takeno S, Noguchi T, Kikuchi R, Sato T, Uchida Y and Yokoyama S: Analysis of the survival period in resectable stage IV gastric cancer. Ann Surg Oncol 8: 215-221, 2001.

3. Bouriez D, Giraud J, Gronnier C and Varon C: Efficiency of All-Trans Retinoic Acid on Gastric Cancer: A Narrative Literature Review. Int J Mol Sci 19: 19, 2018.

4. Li X, Liu Y, Cao B, Liu B, Bai T, Li X, Mei L and Che X: Metastatic lymph node ratio and prognosis of gastric cancer at different pT stages. Hepatogastroenterology 62: 507-511, 2015.

5. Wang Q, Chen Q, Zhu L, Chen M, Xu W, Panday S, Wang Z, Li A Røe OD, Chen R, et al: JWA regulates TRAIL-induced apoptosis via MARCH8-mediated DR4 ubiquitination in cisplatin-resistant gastric cancer cells. Oncogenesis 6: e353, 2017.

6. Liu LP, Sheng XP, Shuai TK, Zhao YX, Li B and Li YM: Helicobacter pylori promotes invasion and metastasis of gastric cancer by enhancing heparanase expression. World $\mathrm{J}$ Gastroenterol 24: 4565-4577, 2018.

7. Xie Y, Jin P, Sun X, Jiao T, Zhang Y, Li Y and Sun M: SIX1 is upregulated in gastric cancer and regulates proliferation and invasion by targeting the ERK pathway and promoting epithelial-mesenchymal transition. Cell Biochem Funct: Oct 31, 2018 (Epub ahead of print).

8. Song Y, Mu L, Han X, Liu X and Fu S: siRNA targeting stathmin inhibits invasion and enhances chemotherapy sensitivity of stem cells derived from glioma cell lines. Acta Biochim Biophys Sin (Shanghai) 46: 1034-1040, 2014.

9. Wang F, Xuan XY, Yang X, Cao L, Pang LN, Zhou R, Fan QX and Wang LX: Stathmin is a marker of progression and poor prognosis in esophageal carcinoma. Asian Pac J Cancer Prev 15: 3613-3618, 2014.

10. Liu X, Liu H, Liang J, Yin B, Xiao J, Li J, Feng D and Li Y: Stathmin is a potential molecular marker and target for the treatment of gastric cancer. Int J Clin Exp Med 8: 6502-6509, 2015.

11. Lu Y, Liu C, Cheng H, Xu Y, Jiang J, Xu J, Long J, Liu L and $\mathrm{Yu} X$ : Stathmin, interacting with $\mathrm{Nf}-\varkappa \mathrm{B}$, promotes tumor growth and predicts poor prognosis of pancreatic cancer. Curr Mol Med 14: 328-339, 2014.

12. Ke B, Wu LL, Liu N, Zhang RP, Wang CL and Liang H: Overexpression of stathmin 1 is associated with poor prognosis of patients with gastric cancer. Tumour Biol 34: 3137-3145, 2013.

13. Byrne FL, Yang L, Phillips PA, Hansford LM, Fletcher JI, Ormandy CJ, McCarroll JA and Kavallaris M: RNAi-mediated stathmin suppression reduces lung metastasis in an orthotopic neuroblastoma mouse model. Oncogene 33: 882-890, 2014.

14. Lu Y, Liu C, Xu YF, Cheng H, Shi S, Wu CT and Yu XJ: Stathmin destabilizing microtubule dynamics promotes malignant potential in cancer cells by epithelial-mesenchymal transition. Hepatobiliary Pancreat Dis Int 13: 386-394, 2014.

15. Livak KJ and Schmittgen TD: Analysis of relative gene expression data using real-time quantitative PCR and the 2(-Delta Delta C(T)) method. Methods 25: 402-408, 2001.

16. Moriyama T, Ito A, Omote S, Miura Y and Tsumoto H: Heat Resistant Characteristics of Major Royal Jelly Protein 1 (MRJP1) Oligomer. PLoS One 10: e0119169, 2015.

17. Wang ZQ, Cai Q, Hu L, He CY, Li JF, Quan ZW, Liu BY, Li C and Zhu ZG: Long noncoding RNA UCA1 induced by SP1 promotes cell proliferation via recruiting EZH2 and activating AKT pathway in gastric cancer. Cell Death Dis 8: e2839, 2017.

18. Pan T, Chen W, Yuan X, Shen J, Qin C and Wang L: miR-944 inhibits metastasis of gastric cancer by preventing the epithelial-mesenchymal transition via MACC1/Met/AKT signaling. FEBS Open Bio 7: 905-914, 2017.

19. Kim JW, Lee HS, Nam KH, Ahn S, Kim JW, Ahn SH, Park DJ, Kim HH and Lee KW: PIK3CA mutations are associated with increased tumor aggressiveness and Akt activation in gastric cancer. Oncotarget 8: 90948-90958, 2017.

20. Wang C, Jiang J, Ji J, Cai Q, Chen X, Yu Y, Zhu Z and Zhang J: PKM2 promotes cell migration and inhibits autophagy by mediating PI3K/AKT activation and contributes to the malignant development of gastric cancer. Sci Rep 7: 2886, 2017.

21. Song Y, Li ZX, Liu X, Wang R, Li LW and Zhang Q: The Wnt/ $\beta$-catenin and PI3K/Akt signaling pathways promote EMT in gastric cancer by epigenetic regulation via $\mathrm{H} 3$ lysine 27 acetylation. Tumour Biol 39: 1010428317712617, 2017.

22. Zhang X, Tang J, Zhi X, Xie K, Wang W, Li Z, Zhu Y, Yang L, $\mathrm{Xu} \mathrm{H}$ and $\mathrm{Xu} \mathrm{Z}$ : Correction: miR-874 functions as a tumor suppressor by inhibiting angiogenesis through STAT3/VEGF-A pathway in gastric cancer. Oncotarget 8: 29535, 2017. 
23. You W, Tang Q, Zhang C, Wu J, Gu C, Wu Z and Li X: IL-26 promotes the proliferation and survival of human gastric cancer cells by regulating the balance of STAT1 and STAT3 activation. PLoS One 8: e63588, 2013.

24. Zheng L, Chen J, Zhou Z and He Z: Knockdown of long non-coding RNA HOXD-AS1 inhibits gastric cancer cell growth via inactivating the JAK2/STAT3 pathway. Tumour Biol 39: $1010428317705335,2017$.

25. Xu YY, Guo M, Yang LQ, Zhou F, Yu C, Wang A, Pang TH, Wu HY, Zou XP, Zhang WJ, et al: Regulation of CD44v6 expression in gastric carcinoma by the IL-6/STAT3 signaling pathway and its clinical significance. Oncotarget 8: 45848-45861, 2017.

26. Merchant JL: What lurks beneath: IL-11, via Stat3, promotes inflammation-associated gastric tumorigenesis. J Clin Invest 118 $1628-1631,2008$.

27. Zgodziński W, Grywalska E, Surdacka A, Zinkiewicz K, Majewski M, Szczepanek D, Wallner G and Roliński J: Surface CD200 and CD200R antigens on lymphocytes in advanced gastric cancer: A new potential target for immunotherapy. Arch Med Sci 14: 1271-1280, 2018.

28. Jin X, Zhu Z and Shi Y: Metastasis mechanism and gene/protein expression in gastric cancer with distant organs metastasis. Bull Cancer: Oct 8,2014 (Epub ahead of print).

29. Han ZX, Wang HM, Jiang G, Du XP, Gao XY and Pei DS: Overcoming paclitaxel resistance in lung cancer cells via dual inhibition of stathmin and Bcl-2. Cancer Biother Radiopharm 28: 398-405, 2013.

30. Wosnitzer MS, Domingo-Domenech J, Castillo-Martin M, Ritch C, Mansukhani M, Petrylack DP, Benson MC, McKiernan JM and Cordon-Cardo C: Predictive value of microtubule associated proteins tau and stathmin in patients with nonmuscle invasive bladder cancer receiving adjuvant intravesical taxane therapy. J Urol 186: 2094-2100, 2011.

31. Werner HM, Trovik J, Halle MK, Wik E, Akslen LA, Birkeland E, Bredholt T, Tangen IL, Krakstad C and Salvesen HB: Stathmin protein level, a potential predictive marker for taxane treatment response in endometrial cancer. PLoS One 9: e90141, 2014.

32. Kouzu Y, Uzawa K, Koike H, Saito K, Nakashima D, Higo M, Endo Y, Kasamatsu A, Shiiba M, Bukawa H, et al: Overexpression of stathmin in oral squamous-cell carcinoma: Correlation with tumour progression and poor prognosis. Br J Cancer 94: 717-723, 2006.

33. Miceli C, Tejada A, Castaneda A and Mistry SJ: Cell cycle inhibition therapy that targets stathmin in in vitro and in vivo models of breast cancer. Cancer Gene Ther 20: 298-307, 2013.

34. Yuan SF, Chen WJ, Zhu LJ, Zheng WE, Chen H and Xiong JP: Effects of monoclonal antibodies against human stathmin combined with paclitaxel on proliferation of the QG-56 human lung carcinoma cell line. Asian Pac J Cancer Prev 13: 2967-2971, 2012.

35. D'Andrea S, Berton S, Segatto I, Fabris L, Canzonieri V, Colombatti A, Vecchione A, Belletti B and Baldassarre G: Stathmin is dispensable for tumor onset in mice. PLoS One 7: e45561, 2012

36. Ying L, Su D, Zhu J, Ma S, Katsaros D and Yu H: Genotyping of stathmin and its association with clinical factors and surviva in patients with ovarian cancer. Oncol Lett 5: 1315-1320, 2013.

37. Pucci S, Bonanno E, Sesti F, Mazzarelli P, Mauriello A, Ricci F, Zoccai GB, Rulli F, Galatà G and Spagnoli LG: Clusterin in stool: A new biomarker for colon cancer screening? Am J Gastroenterol 104: 2807-2815, 2009.

38. Flanagan L, Whyte L, Chatterjee $\mathrm{N}$ and Tenniswood M: Effects of clusterin over-expression on metastatic progression and therapy in breast cancer. BMC Cancer 10: 107, 2010.

39. Rizzi F and Bettuzzi S: The clusterin paradigm in prostate and breast carcinogenesis. Endocr Relat Cancer 17: R1-R17, 2010

40. Bi J, Guo AL, Lai YR, Li B, Zhong JM, Wu HQ, Xie Z, He YL, Lv ZL, Lau SH, et al: Overexpression of clusterin correlates with tumor progression, metastasis in gastric cancer: A study on tissue microarrays. Neoplasma 57: 191-197, 2010.

41. Xiu P, Xu Z, Liu F, Li Z, Li T, Zou F, Sun X and Li J: Downregulating sCLU enhances the sensitivity of hepatocellular carcinoma cells to gemcitabine by activating the intrinsic apoptosis pathway. Dig Dis Sci 59: 1798-1809, 2014.

42. Wang $C$, Jin $G$, Jin $H$, Wang $N$, Luo Q, Zhang $Y$, Gao D, Jiang K, Gu D, Shen Q, et al: Clusterin facilitates metastasis by EIF3I/Akt/MMP13 signaling in hepatocellular carcinoma. Oncotarget 6: 2903-2916, 2015.
43. Gong F, Peng X, Sang Y, Qiu M, Luo C, He Z, Zhao X and Tong A: Dichloroacetate induces protective autophagy in LoVo cells: Involvement of cathepsin D/thioredoxin-like protein 1 and Akt-mTOR-mediated signaling. Cell Death Dis 4: e913, 2013.

44. Huang WW, Tsai SC, Peng SF, Lin MW, Chiang JH, Chiu YJ, Fushiya S, Tseng MT and Yang JS: Kaempferol induces autophagy through AMPK and AKT signaling molecules and causes G2/M arrest via downregulation of CDK1/cyclin B in SK-HEP-1 human hepatic cancer cells. Int J Oncol 42: 2069-2077, 2013.

45. Zhang Y, Huang W, Ran Y, Xiong Y, Zhong Z, Fan X, Wang Z and Ye Q: miR-582-5p inhibits proliferation of hepatocellular carcinoma by targeting CDK1 and AKT3. Tumour Biol 36: 8309-8316, 2015

46. Tibes R, McDonagh KT, Lekakis L, Bogenberger JM, Kim S, Frazer N, Mohrland S, Bassett D, Garcia R, Schroeder K, et al: Phase I study of the novel Cdc2/CDK1 and AKT inhibitor terameprocol in patients with advanced leukemias. Invest New Drugs 33: 389-396, 2015

47. Li B, Xu W, Luo C, Gozal D and Liu R: VEGF-induced activation of the PI3-K/Akt pathway reduces mutant SOD1-mediated motor neuron cell death. Brain Res Mol Brain Res 111: 155-164, 2003.

48. Zhang B, Zhang K, Liu Z, Hao F, Wang M, Li X, Yin Z and Liang H: Secreted clusterin gene silencing enhances chemosensitivity of a549 cells to cisplatin through AKT and ERK1/2 pathways in vitro. Cell Physiol Biochem 33: 1162-1175, 2014.

49. Ma X and Bai Y: IGF-1 activates the P13K/AKT signaling pathway via upregulation of secretory clusterin. Mol Med Rep 6: 1433-1437, 2012

50. Shim YJ, Kang BH, Jeon HS, Park IS, Lee KU, Lee IK, Park GH, Lee KM, Schedin P and Min BH: Clusterin induces matrix metalloproteinase-9 expression via ERK1/2 and PI3K/Akt/NF- $x \mathrm{~B}$ pathways in monocytes/macrophages. J Leukoc Biol 90: 761-769, 2011.

51. Yadav P, Selvaraj BT, Bender FL, Behringer M, Moradi M, Sivadasan R, Dombert B, Blum R, Asan E, Sauer M, et al: Neurofilament depletion improves microtubule dynamics via modulation of Stat3/stathmin signaling. Acta Neuropathol 132: 93-110, 2016

52. Morris EJ, Kawamura E, Gillespie JA, Balgi A, Kannan N, Muller WJ, Roberge M and Dedhar S: Stat3 regulates centrosome clustering in cancer cells via Stathmin/PLK1. Nat Commun 8: 15289, 2017.

53. Ng DC, Lin BH, Lim CP, Huang G, Zhang T, Poli V and Cao X: Stat 3 regulates microtubules by antagonizing the depolymerization activity of stathmin. J Cell Biol 172: 245-257, 2006.

54. Verma NK, Dourlat J, Davies AM, Long A, Liu WQ, Garbay C, Kelleher D and Volkov Y: STAT3-stathmin interactions control microtubule dynamics in migrating T-cells. J Biol Chem 284: $12349-12362,2009$.

55. Ebrahimpour S and Saadat I: Association of CAT C-262T and SOD1 A251G single nucleotide polymorphisms susceptible to gastric cancer. Mol Biol Res Commun 3: 223-229, 2014.

56. Kantsaliev AL, Kozyreva EA, Kushlinskiı̆ NE, Rottenberg VI, Klimenkov AA and Vasil'ev AV: Cathepsin D activity in gastric cancer. Vopr Onkol 40: 40-46, 1994 (In Russian).

57. Saku T, Sakai H, Tsuda N, Okabe H, Kato Y and Yamamoto K: Cathepsins D and E in normal, metaplastic, dysplastic, and carcinomatous gastric tissue: An immunohistochemical study. Gut 31: 1250-1255, 1990.

58. Gao SY, Li J, Qu XY, Zhu N and Ji YB: Downregulation of Cdk1 and cyclinB1 expression contributes to oridonin-induced cell cycle arrest at $\mathrm{G} 2 / \mathrm{M}$ phase and growth inhibition in SGC-7901 gastric cancer cells. Asian Pac J Cancer Prev 15: 6437-6441, 2014

59. Zeng Q, Zhao Y, Yang Y, Chen XX, Wang G, Zhang P, Cui Y, $\mathrm{Su} \mathrm{S}$ and Li K: Expression of Cystatin C in human stomach neoplasms. Mol Med Rep 3: 607-611, 2010.

60. Allgayer H, Babic R, Grützner KU, Beyer BC, Tarabichi A, Wilhelm Schildberg F and Heiss MM: An immunohistochemical assessment of cathepsin D in gastric carcinoma: Its impact on clinical prognosis. Cancer 80: 179-187, 1997.

61. Lee MH, Cho Y, Kim DH, Woo HJ, Yang JY, Kwon HJ, Yeon MJ, Park M, Kim SH, Moon C, et al: Menadione induces G2/M arrest in gastric cancer cells by down-regulation of CDC25C and proteasome mediated degradation of CDK1 and cyclin B1. Am J Transl Res 8: 5246-5255, 2016

62. Liu H, Lu J, Hua Y, Zhang P, Liang Z, Ruan L, Lian C, Shi H, Chen K and Tu Z: Targeting heat-shock protein 90 with ganetespib for molecularly targeted therapy of gastric cancer. Cell Death Dis 6: e1595, 2015. 